\title{
Existence of periodic solutions for a higher-order neutral difference equation
}

\author{
Jiao-Ling Zhang ${ }^{1}$ and Gen-Qiang Wang ${ }^{2 *}$
}

${ }^{*}$ Correspondence: W7633@hotmail.com

${ }^{2}$ Department of General Education, Tianhe College, Guangdong Polytechnic Normal University, Guangzhou, P.R. China

Full list of author information is available at the end of the article

\begin{abstract}
Based on a continuation theorem of Mawhin, the existence of a periodic solution for a higher-order nonlinear neutral difference equation is studied. Our conclusion is new and interesting.
\end{abstract}

MSC: $39 \mathrm{~A} 11$

Keywords: Periodic solutions; Neutral difference equation; Nonlinear; Continuation theorem

\section{Introduction}

The periodic solution theory of differential equation and difference equation has important academic value and application background. It has aroused people's great concern, and many good results have been achieved. For example, see articles [1-8] and the references therein. However, as far as we know, the results of the periodic solutions of neutral difference equations are relatively few (see $[7,8]$ ).

In this paper, we study the periodic solutions of a higher-order nonlinear neutral difference equation of the form

$$
\Delta^{k}\left[u_{n}+c u_{n-\sigma}\right]=g_{n}\left(u_{n-\tau_{1}}, u_{n-\tau_{2}}, \ldots, u_{n-\tau_{l}}\right), \quad n \in Z,
$$

where $k$ is a positive integer, $c$ is a real number different from -1 and $1, \sigma$ and $\tau_{i}$ are integers for $i \in\{1,2, \ldots, l\}, g_{n} \in C\left(R^{l}, R\right)$ for $n \in Z$ and $g_{n}=g_{n+\omega}$, where $\omega$ is a positive integer which satisfies $\omega \geq 2$. We use a continuity theorem to give some criteria for the existence of a periodic solution of (1), and our conclusion is new and interesting.

A solution of (1) is a real sequence of the form $x=\left\{x_{n}\right\}_{n \in Z}$ which renders (1) into an identity after substitution. As usual, a solution of (1) of the form $x=\left\{x_{n}\right\}_{n \in Z}$ is said to be $\omega$-periodic if $x_{n+\omega}=x_{n}$ for $n \in Z$.

We also state Mawhin's continuation theorem (see [1]). Let $X$ and $Y$ be two Banach spaces, and $L: \operatorname{Dom} L \subset X \rightarrow Y$ is a linear mapping and $N: X \rightarrow Y$ is a continuous mapping. The mapping $L$ is called a Fredholm mapping of index zero if $\operatorname{dim} \operatorname{Ker} L=$ codim $\operatorname{Im} L<+\infty$, and $\operatorname{Im} L$ is closed in $Y$. If $L$ is a Fredholm mapping of index zero, then there exist continuous projectors $P: X \rightarrow X$ and $Q: Y \rightarrow Y$ such that $\operatorname{Im} P=\operatorname{Ker} L$ and $\operatorname{Im} L=\operatorname{Ker} Q=\operatorname{Im}(I-Q)$. It follows that $L_{\mid \operatorname{Dom} L \cap \operatorname{Ker} P}:(I-P) X \rightarrow \operatorname{Im} L$ has an inverse which is denoted by $K_{p}$. If $\Omega$ is an open and bounded subset of $X$, then the mapping $N$ is called

(c) The Author(s) 2018. This article is distributed under the terms of the Creative Commons Attribution 4.0 International License (http://creativecommons.org/licenses/by/4.0/), which permits unrestricted use, distribution, and reproduction in any medium, provided you give appropriate credit to the original author(s) and the source, provide a link to the Creative Commons license, and indicate if changes were made. 
$L$-compact on $\bar{\Omega}$ when $Q N(\bar{\Omega})$ is bounded and $K_{P}(I-Q) N: \bar{\Omega} \rightarrow X$ is compact. Since $\operatorname{Im} Q$ is isomorphic to $\operatorname{Ker} L$, there exists an isomorphism $J: \operatorname{Im} Q \rightarrow \operatorname{Ker} L$.

Theorem A (Mawhin's continuation theorem [1]) Let L be a Fredholm mapping of index zero, and let $N$ be L-compact on $\bar{\Omega}$. Suppose

(I) for each $\lambda \in(0,1), x \in \partial \Omega, L x \neq \lambda N x$; and

(II) for each $x \in \partial \Omega \cap \operatorname{Ker} L, Q N x \neq 0$ and $\operatorname{deg}(J Q N, \Omega \cap \operatorname{Ker} L, 0) \neq 0$.

Then the equation $L x=N x$ has at least one solution in $\bar{\Omega} \cap \operatorname{Dom} L$.

\section{Main result}

The main result of this paper is as follows:

Theorem 2.1 Let $|c| \neq 1$. Assume that there exist constants $D>0, \alpha \geq 0$, and $\beta \geq 0$ such that

(I) $\left|g_{n}\left(x_{1}, x_{2}, \ldots, x_{l}\right)\right| \leq \beta \max _{1 \leq i \leq l}\left|x_{i}\right|+\alpha$ for $n \in Z$ and $\left(x_{1}, x_{2}, \ldots, x_{l}\right)^{T} \in R^{l}$,

(II) $g_{n}\left(x_{1}, x_{2}, \ldots, x_{l}\right)>0$ for $n \in Z$ and $x_{1}, x_{2}, \ldots, x_{l} \geq D$,

(III) $g_{n}\left(x_{1}, x_{2}, \ldots, x_{l}\right)<0$ for $n \in Z$ and $x_{1}, x_{2}, \ldots, x_{l} \leq-D$.

Then the higher-order neutral difference equation (1) has an $\omega$-periodic solution when $\omega^{k} \beta<2^{k}|1-| c||$.

Remark 2.1 When $g_{n}$ in (1) is replaced by $-g_{n}$, the result of Theorem 2.1 still holds.

Next, some preparations are presented to prove our theorems. Let $X_{\omega}$ be the Banach space of all real $\omega$-periodic sequences of the form $x=\left\{x_{n}\right\}_{n \in Z}$ and endowed with the usual linear structure as well as the norm $|x|_{\infty}=\max _{1 \leq i \leq \omega}\left|x_{i}\right|$.

Define the mappings $L: X_{\omega} \rightarrow X_{\omega}$ and $N: X_{\omega} \rightarrow X_{\omega}$ respectively by

$$
(L x)_{n}=\Delta^{k}\left[x_{n}+c x_{n-\sigma}\right], \quad n \in Z,
$$

and

$$
(N x)_{n}=g_{n}\left(x_{n-\tau_{1}}, x_{n-\tau_{2}}, \ldots, x_{n-\tau_{l}}\right), \quad n \in Z
$$

It is easy to see that $L$ is a linear mapping. Similar to the paper [8], in case $|c| \neq 1$, direct calculation shows that $\operatorname{Ker} L=\left\{x \in X_{\omega} \mid x_{n}=x_{0}, n \in Z\right\}$. Since $\operatorname{dim} X_{\omega}=\omega$ and $L: X_{\omega} \rightarrow X_{\omega}$ is a linear mapping, by the knowledge of linear algebra, we know that $\operatorname{dim} \operatorname{Ker} L \bigoplus \operatorname{dim} \operatorname{Im} L=$ $\operatorname{dim} X_{\omega}$. It is easy to see that $\operatorname{dim} \operatorname{Ker} L=\operatorname{codim} \operatorname{Im} L=1$ and $\operatorname{dim} \operatorname{Im} L=\omega-1$. It follows that $\operatorname{Im} L$ is closed in $X_{\omega}$. Thus $L$ is a Fredholm mapping of index zero. Now, we assert that

$$
\operatorname{Ker} L \bigoplus \operatorname{Im} L=X_{\omega}
$$

To do that, we just have to prove that

$$
\operatorname{Ker} L \cap \operatorname{Im} L=0 .
$$

Indeed, if $y=\left\{y_{n}\right\}_{n \in Z} \in \operatorname{Im} L$, then there is $x=\left\{x_{n}\right\}_{n \in Z} \in X_{\omega}$ such that

$$
y_{n}=\Delta^{k}\left[x_{n}+c x_{n-\sigma}\right], \quad n \in Z .
$$


Thus

$$
\sum_{i=1}^{\omega} y_{i}=\sum_{i=1}^{\omega} \Delta^{k}\left[x_{i}+c x_{i-\sigma}\right]
$$

Note that $x=\left\{x_{n}\right\}_{n \in Z} \in X_{\omega}$. It follows that $\left\{\Delta^{k-1} x_{n}\right\}_{n \in Z} \in X_{\omega}$. Furthermore, direct calculation shows that

$$
\begin{aligned}
\sum_{i=1}^{\omega} \Delta^{k} x_{i}= & {\left[\Delta^{k-1} x_{2}-\Delta^{k-1} x_{1}\right]+\left[\Delta^{k-1} x_{3}-\Delta^{k-1} x_{2}\right]+\cdots } \\
& +\left[\Delta^{k-1} x_{\omega}-\Delta^{k-1} x_{\omega-1}\right]+\left[\Delta^{k-1} x_{\omega+1}-\Delta^{k-1} x_{\omega}\right] \\
= & \Delta^{k-1} x_{\omega+1}-\Delta^{k-1} x_{1}=\Delta^{k-1} x_{1}-\Delta^{k-1} x_{1}=0 .
\end{aligned}
$$

By (7) and (8), we have

$$
\sum_{i=1}^{\omega} y_{i}=\sum_{i=1}^{\omega} \Delta^{k}\left[x_{i}+c x_{i-\sigma}\right]=\sum_{i=1}^{\omega} \Delta^{k} x_{i}+c \sum_{i=1}^{\omega} \Delta^{k} x_{i-\sigma}=0+0=0
$$

We see that for any $u=\left\{u_{n}\right\}_{n \in Z} \in \operatorname{Ker} L \cap \operatorname{Im} L$, then $u=\left\{u_{n}\right\}_{n \in Z} \in \operatorname{Ker} L$ and $u=\left\{u_{n}\right\}_{n \in Z} \in$ $\operatorname{Im} L$. Because of $u=\left\{u_{n}\right\}_{n \in Z} \in \operatorname{Ker} L$ and $\operatorname{Ker} L=\left\{x \in X_{\omega} \mid x_{n}=x_{0}, n \in Z\right\}$, thus for any $n \in Z$, we have

$$
u_{n}=\frac{1}{\omega} \sum_{i=1}^{\omega} u_{i}
$$

On the other hand, since $u=\left\{u_{n}\right\}_{n \in Z} \in \operatorname{Im} L$, by (9), we have

$$
\sum_{i=1}^{\omega} u_{i}=0
$$

By (10) and (11), we see that, for any $n \in Z, u_{n}=0$. This implies that (5) is true, that (4) is true. Now, for any $u=\left\{u_{n}\right\}_{n \in Z} \in X_{\omega}$, if

$$
u=x+y,
$$

where $x=\left\{x_{n}\right\}_{n \in Z} \in \operatorname{Ker} L$ and $y=\left\{y_{n}\right\}_{n \in Z} \in \operatorname{Im} L$, then

$$
x_{n}=\frac{1}{\omega} \sum_{i=1}^{\omega} u_{i}, \quad n \in Z
$$

and

$$
y_{n}=u_{n}-\frac{1}{\omega} \sum_{i=1}^{\omega} u_{i}, \quad n \in Z
$$

As in paper [8], we define $P=Q: X_{\omega} \rightarrow X_{\omega}$ by

$$
(P x)_{n}=(Q x)_{n}=\frac{1}{\omega} \sum_{i=1}^{\omega} x_{i}, \quad n \in Z
$$


The operators $P$ and $Q$ are projections. We have $\operatorname{Im} P=\operatorname{Ker} L, \operatorname{Ker} Q=\operatorname{Im} L$, and $X_{\omega}=$ $\operatorname{Ker} P \bigoplus \operatorname{Ker} L=\operatorname{Im} L \bigoplus \operatorname{Im} Q$. It follows that $L_{\mid \operatorname{Dom} L \cap \operatorname{Ker} P}:(I-P) X_{\omega} \rightarrow \operatorname{Im} L$ has an inverse which is denoted by $K_{p}$. By (3) and (13), we see that, for any $x=\left\{x_{n}\right\}_{n \in Z} \in X_{\omega}$,

$$
(Q N x)_{n}=\frac{1}{\omega} \sum_{i=1}^{\omega} g_{i}\left(x_{i-\tau_{1}}, x_{i-\tau_{2}}, \ldots, x_{i-\tau_{l}}\right), \quad n \in Z
$$

and

$$
((I-Q) N x)_{n}=g_{n}\left(x_{n-\tau_{1}}, x_{n-\tau_{2}}, \ldots, x_{n-\tau_{l}}\right)-\frac{1}{\omega} \sum_{i=1}^{\omega} g_{i}\left(x_{i-\tau_{1}}, x_{i-\tau_{2}}, \ldots, x_{i-\tau_{l}}\right), \quad n \in Z .
$$

Since the Banach space $X_{\omega}$ is finite dimensional, $K_{p}$ is linear. By relations (14) and (15), we see that $Q N$ and $K_{p}(I-Q) N$ are continuous on $X_{\omega}$ and take bounded sets into bounded sets respectively. Thus, we know that if $\Omega$ is an open and bounded subset of $X_{\omega}$, then the mapping $N$ is called $L$-compact on $\bar{\Omega}$.

Lemma 2.1 (see [7]) Let $\left\{u_{n}\right\}_{n \in Z}$ be a real $\omega$-periodic sequence, then we have

$$
\max _{1 \leq s, t \leq \omega}\left|u_{s}-u_{t}\right| \leq \frac{1}{2} \sum_{n=1}^{\omega}\left|\Delta u_{n}\right|
$$

where the constant factor $1 / 2$ is the best possible.

Lemma 2.2 (see [7]) Let $\left\{u_{n}\right\}_{n \in Z}$ be a real $\omega$-periodic sequence, then

$$
\sum_{n=1}^{\omega}\left|\Delta u_{n}\right| \leq \frac{\omega}{2} \sum_{n=1}^{\omega}\left|\Delta^{2} u_{n}\right|
$$

Lemma 2.3 (see [7]) If $|c| \neq 1$ and $\left\{u_{n}\right\}_{n \in Z}$ is a real $\omega$-periodic sequence, then

$$
\max _{1 \leq s, t \leq \omega}\left|u_{s}-u_{t}\right| \leq \frac{\omega^{k-1}}{2^{k}|1-| c||} \sum_{n=1}^{\omega}\left|\Delta^{k}\left[u_{n}+c u_{n-\sigma}\right]\right| .
$$

Proof Note that

$$
\begin{aligned}
\sum_{n=1}^{\omega}\left|\Delta^{k}\left[u_{n}+c u_{n-\sigma}\right]\right| & \geq\left|\sum_{n=1}^{\omega}\right| \Delta^{k} u_{n}|-| c\left|\sum_{n=1}^{\omega}\right| \Delta^{k} u_{n-\sigma}|| \\
& =|1-| c|| \sum_{n=1}^{\omega}\left|\Delta^{k} u_{n}\right| .
\end{aligned}
$$

It follows that

$$
\sum_{n=1}^{\omega}\left|\Delta^{k} u_{n}\right| \leq \frac{1}{|1-| c||} \sum_{n=1}^{\omega}\left|\Delta^{k}\left[u_{n}+c u_{n-\sigma}\right]\right| .
$$


If $k=1$, by Lemma 2.1 and (19), then

$$
\max _{1 \leq s, t \leq \omega}\left|u_{s}-u_{t}\right| \leq \frac{1}{2|1-| c||} \sum_{n=1}^{\omega}\left|\Delta\left[u_{n}+c u_{n-\sigma}\right]\right|
$$

If $k \geq 2$, by Lemma 2.2 , then

$$
\begin{aligned}
\sum_{i=1}^{\omega}\left|\Delta u_{i}\right| & \leq \frac{\omega}{2} \sum_{n=1}^{\omega}\left|\Delta^{2} u_{n}\right| \\
& \leq \frac{\omega^{2}}{2^{2}} \sum_{n=1}^{\omega}\left|\Delta^{3} u_{n}\right| \leq \cdots \\
& \leq \frac{\omega^{k-1}}{2^{k-1}} \sum_{n=1}^{\omega}\left|\Delta^{k} u_{n}\right| .
\end{aligned}
$$

In view of (19) and (20), we have

$$
\max _{1 \leq s, t \leq \omega}\left|u_{s}-u_{t}\right| \leq \frac{\omega^{k-1}}{2^{k}} \sum_{n=1}^{\omega}\left|\Delta^{k} u_{n}\right| \leq \frac{\omega^{k-1}}{2^{k}|1-| c||} \sum_{n=1}^{\omega}\left|\Delta^{k}\left[u_{n}+c u_{n-\sigma}\right]\right| .
$$

The proof is completed.

Proof of Theorem 2.1 Consider the system

$$
(L x)_{n}=\lambda(N x)_{n}, \quad n \in Z,
$$

where $\lambda \in(0,1)$ is a parameter. Let $u \in X_{\omega}$ be a solution of (21). By (2), (3), and (21),

$$
\Delta^{k}\left[u_{n}+c u_{n-\sigma}\right]=\lambda g_{n}\left(u_{n-\tau_{1}}, u_{n-\tau_{2}}, \ldots, u_{n-\tau_{l}}\right), \quad n \in Z
$$

Let $u_{\xi}=\max _{1 \leq n \leq \omega} u_{n}$ and $u_{\eta}=\min _{1 \leq n \leq \omega} u_{n}$. By Lemma 2.3 and (21),

$$
\begin{aligned}
u_{\xi}-u_{\eta} & =\max _{1 \leq s, t \leq \omega}\left|u_{s}-u_{t}\right| \\
& \leq \frac{\omega^{k-1}}{2^{k}|1-| c||} \sum_{n=1}^{\omega}\left|\Delta^{k}\left[u_{n}+c u_{n-\sigma}\right]\right| \\
& \leq \frac{\omega^{k-1}}{2^{k}|1-| c||} \sum_{n=1}^{\omega}\left|g_{n}\left(u_{n-\tau_{1}}, u_{n-\tau_{2}}, \ldots, u_{n-\tau_{l}}\right)\right| .
\end{aligned}
$$

If there exists a constant $m \in\{1,2, \ldots, \omega\}$ such that $\left|u_{m}\right|<D$, by (23), for any $n \in Z$, then

$$
\begin{aligned}
\left|u_{n}\right| & \leq\left|u_{m}\right|+\left|u_{n}-u_{m}\right| \\
& \leq D+\max _{1 \leq s, t \leq \omega}\left|u_{s}-u_{t}\right| \\
& \leq D+\frac{\omega^{k-1}}{2^{k}|1-| c||} \sum_{n=1}^{\omega}\left|g_{n}\left(u_{n-\tau_{1}}, u_{n-\tau_{2}}, \ldots, u_{n-\tau_{l}}\right)\right| .
\end{aligned}
$$


Otherwise by (22),

$$
\sum_{n=1}^{\omega} g_{n}\left(u_{n-\tau_{1}}, u_{n-\tau_{2}}, \ldots, u_{n-\tau_{l}}\right)=0
$$

In view of conditions (II), (III) and (25), we know $u_{\xi} \geq D$ and $u_{\eta} \leq-D$. By (23),

$$
\begin{aligned}
u_{\xi} & \leq u_{\eta}+\frac{\omega^{k-1}}{2^{k}|1-| c||} \sum_{n=1}^{\omega}\left|g_{n}\left(u_{n-\tau_{1}}, u_{n-\tau_{2}}, \ldots, u_{n-\tau_{l}}\right)\right| \\
& \leq-D+\frac{\omega^{k-1}}{2^{k}|1-| c||} \sum_{n=1}^{\omega}\left|g_{n}\left(u_{n-\tau_{1}}, u_{n-\tau_{2}}, \ldots, u_{n-\tau_{l}}\right)\right|
\end{aligned}
$$

and

$$
\begin{aligned}
u_{\eta} & \geq u_{\xi}-\frac{\omega^{k-1}}{2^{k}|1-| c||} \sum_{n=1}^{\omega}\left|g_{n}\left(u_{n-\tau_{1}}, u_{n-\tau_{2}}, \ldots, u_{n-\tau_{l}}\right)\right| \\
& \geq D-\frac{\omega^{k-1}}{2^{k}|1-| c||} \sum_{n=1}^{\omega}\left|g_{n}\left(u_{n-\tau_{1}}, u_{n-\tau_{2}}, \ldots, u_{n-\tau_{l}}\right)\right| .
\end{aligned}
$$

By (26) and (27), for any $n \in Z$,

$$
\begin{array}{r}
D-\frac{\omega^{k-1}}{2^{k}|1-| c||} \sum_{n=1}^{\omega}\left|g_{n}\left(u_{n-\tau_{1}}, u_{n-\tau_{2}}, \ldots, u_{n-\tau_{l}}\right)\right| \leq u_{\eta} \leq u_{n} \leq u_{\xi} \\
\leq-D+\frac{\omega^{k-1}}{2^{k}|1-| c||} \sum_{n=1}^{\omega}\left|g_{n}\left(u_{n-\tau_{1}}, u_{n-\tau_{2}}, \ldots, u_{n-\tau_{l}}\right)\right| .
\end{array}
$$

From (24) and (28), for any $n \in Z$, we have

$$
\left|u_{n}\right| \leq D+\frac{\omega^{k-1}}{2^{k}|1-| c||} \sum_{n=1}^{\omega}\left|g_{n}\left(u_{n-\tau_{1}}, u_{n-\tau_{2}}, \ldots, u_{n-\tau_{l}}\right)\right| \text {. }
$$

It follows that

$$
|u|_{\infty} \leq D+\frac{\omega^{k-1}}{2^{k}|1-| c||} \sum_{n=1}^{\omega}\left|g_{n}\left(u_{n-\tau_{1}}, u_{n-\tau_{2}}, \ldots, u_{n-\tau_{l}}\right)\right|
$$

By condition (I),

$$
\begin{aligned}
\sum_{n=1}^{\omega}\left|g_{n}\left(u_{n-\tau_{1}}, u_{n-\tau_{2}}, \ldots, u_{n-\tau_{l}}\right)\right| & \leq \omega \beta \max _{1 \leq i \leq l}\left|u_{n-\tau_{i}}\right|+\omega \alpha \\
& \leq \omega \beta|u|_{\infty}+\omega \alpha
\end{aligned}
$$

By (29) and (30),

$$
|u|_{\infty} \leq \frac{C}{1-\rho}
$$


where $C=D+\frac{\omega^{k} \alpha}{2^{k}|1-| c||}$ and $\rho=\frac{\omega^{k} \beta}{2^{k}|1-| c||}$.

Set

$$
\Omega=\left\{u \in X_{\omega}:|u|_{\infty}<\bar{D}\right\}
$$

where $\bar{D}$ is a fixed number which satisfies $\bar{D}>D+\frac{C}{1-\rho}$. We have that $\Omega$ is an open and bounded subset of $X_{\omega}$. By (31), for each $\lambda \in(0,1), u \in \partial \Omega, L u \neq \lambda N u$. If $u \in \partial \Omega \cap \operatorname{Ker} L$, then $u=\{\bar{D}\}_{n \in Z}$ or $u=\{-\bar{D}\}_{n \in Z}$. By (13),

$$
(Q N u)_{n}=\frac{1}{\omega} \sum_{i=1}^{\omega} g_{i}\left(u_{i-\tau_{1}}, u_{i-\tau_{2}}, \ldots, u_{i-\tau_{l}}\right) \neq 0, \quad n \in Z .
$$

In particular, we see that if $u=\{\bar{D}\}_{n \in Z}$, then

$$
(Q N u)_{n}=\frac{1}{\omega} \sum_{i=1}^{\omega} g_{i}(\bar{D}, \bar{D}, \ldots, \bar{D})>0, \quad n \in Z,
$$

and if $u=\{-\bar{D}\}_{n \in Z}$, then

$$
(Q N u)_{n}=\frac{1}{\omega} \sum_{i=1}^{\omega} g_{i}(-\bar{D},-\bar{D}, \ldots, \overline{-D})<0, \quad n \in Z
$$

This indicates

$$
\operatorname{deg}(Q N, \Omega \cap \operatorname{Ker} L, 0) \neq 0 \text {. }
$$

By Theorem A, we see that the equation $L x=N x$ has at least one solution in $\bar{\Omega} \cap \operatorname{Dom} L$. In other words, (1) has an $\omega$-periodic solution. The proof is completed.

\section{Example}

Example 3.1 The difference equation

$$
\Delta^{4}\left[u_{n}+\frac{1}{3} u_{n-2}\right]=\frac{10}{243}\left[2-\sin \left(\frac{2 n \pi}{3}\right)\right]\left(u_{n-2}\right)^{\frac{1}{3}}\left(u_{n-1}\right)^{\frac{1}{3}}\left(u_{n}\right)^{\frac{1}{3}}
$$

is one of the form (1), where $k=4, c=\frac{1}{3}, \sigma=2, l=3, \tau_{1}=2, \tau_{2}=1, \tau_{3}=0$, and

$$
g_{n}\left(u_{1}, u_{2}, u_{3}\right)=\frac{10}{243}\left[2-\sin \left(\frac{2 n \pi}{3}\right)\right]\left(u_{1}\right)^{\frac{1}{3}}\left(u_{2}\right)^{\frac{1}{3}}\left(u_{3}\right)^{\frac{1}{3}}
$$

We can prove that (32) has a 3-periodic nontrivial solution. Indeed, let $D=1, \beta=\frac{10}{81}$, and $\alpha=1$. Then the conditions of Theorem 2.1 are satisfied. Therefore (32) has a 3-periodic solution. Furthermore, the solution is nontrivial since $g_{n}(0,0,0)$ is not identically zero. 
Competing interests

The authors declare that they have no competing interests.

\section{Authors' contributions}

JLZ and GQW worked together in the derivation of the mathematical results. Both authors read and approved the final manuscript.

\section{Author details}

${ }^{1}$ School of Mathematics and Systems Science, Guangdong Polytechnic Normal University, Guangzhou, P.R. China.

${ }^{2}$ Department of General Education, Tianhe College, Guangdong Polytechnic Normal University, Guangzhou, P.R. China.

\section{Publisher's Note}

Springer Nature remains neutral with regard to jurisdictional claims in published maps and institutional affiliations.

Received: 25 July 2018 Accepted: 14 November 2018 Published online: 05 December 2018

\section{References}

1. Gaines, R.E., Mawhin, J.L.: Coincidence Degree and Nonlinear Differential Equations. Lecture Notes in Math., vol. 568 (1977)

2. Gopalsamy, K., He, X., Wen, L.: On a periodic neutral logistic equation. Glasg. Math. J. 33, $281-286$ (1991)

3. Wang, G.Q., Yan, J.R.: Existence of periodic solutions for $n$th order neutral differential equations with multiple variable lags. Acta Math. Sci. 26(2A), 306-313 (2006) (In Chinese)

4. Elaydi, S.: Periodic solutions of difference equations. J. Differ. Equ. Appl. 6(2), 203-232 (2000)

5. Wang, G.Q., Chen, S.S.: Periodic solutions of higher order nonlinear difference equations via a continuation theorem. Georgian Math. J. 12(3), 539-550 (2005)

6. Wang, G.Q., Chen, S.S.: Positive periodic solutions for nonlinear difference equations via a continuation theorem. Adv. Differ. Equ. 4, 311-320 (2004)

7. Wang, G.Q., Chen, S.S.: Periodic solutions of a neutral difference system. Bol. Soc. Parana. Mat. 22(2), 117-126 (2004)

8. Wang, G.Q.: Steady State Solutions of Neural Networks and Periodic Solutions of Difference Equations. Jinan University Press, Guangzhou (2012) (in Chinese)

\section{Submit your manuscript to a SpringerOpen ${ }^{\circ}$ journal and benefit from:}

- Convenient online submission

- Rigorous peer review

- Open access: articles freely available online

High visibility within the field

Retaining the copyright to your article 